\title{
Journal of Service Research
}

http://jsr.sagepub.com

\section{Customer Orientation: Effects on Customer Service Perceptions and Outcome Behaviors \\ Michael K. Brady and J. Joseph Cronin, Jr. \\ Journal of Service Research 2001; 3; 241 \\ DOI: $10.1177 / 109467050133005$ \\ The online version of this article can be found at: http://jsr.sagepub.com/cgi/content/abstract/3/3/241}

\author{
Published by: \\ (S)SAE \\ http://www.sagepublications.com \\ On behalf of: \\ Center for Excellence in Service, University of Maryland
}

Additional services and information for Journal of Service Research can be found at:

Email Alerts: http://jsr.sagepub.com/cgi/alerts

Subscriptions: http://jsr.sagepub.com/subscriptions

Reprints: http://www.sagepub.com/journalsReprints.nav

Permissions: http://www.sagepub.com/journalsPermissions.nav

Citations http://jsr.sagepub.com/cgi/content/refs/3/3/241 


\title{
Customer Orientation Effects on Customer Service Perceptions and Outcome Behaviors
}

\author{
Michael K. Brady \\ Boston College
}

\section{J. Joseph Cronin, Jr.}

Florida State University

This study investigates the effect of being customer oriented on service performance perceptions and outcome behaviors. Specifically, the focus is on identifying the influence that being perceived as a customer-oriented firm has on consumer quality perceptions, customer satisfaction, and service value. The impact of being customer oriented on consumers' outcome behaviors is also investigated. Responses from 649 consumers indicate that customer orientation is directly related to customers' evaluations of employee service performance, physical goods, and servicescapes. Indirect effects on organizational quality, customer satisfaction, value attributions, and outcome behaviors are also reported. The implications of the research are discussed, as are the limitations.

It is widely acknowledged that successful organizations need to have a customer-oriented business culture (e.g., Athanassopoulos 2000; Deshpandé, Farley, and Webster 1993; Houston 1986; Parasuraman 1987; Shapiro 1988; F. E. Webster 1988). In fact, during the four decades since the introduction of the marketing concept, a customer orientation ${ }^{1}$ has been identified as a cornerstone of the theory and practice of marketing management

1. The terms market oriented, market driven, and customer focused tend to be considered synonymous (e.g., Deshpandé, Farley, and Webster 1993; Deshpandé and Webster 1989; Shapiro 1988; Slater and Narver 1995) and are so used in this article.

Journal of Service Research, Volume 3, No. 3, February 2001 241-251 (C) 2001 Sage Publications, Inc.
(Jaworski and Kohli 1993). In large part, this attention is a result of the explicit assumption that customer-oriented firms outperform competitors by anticipating the developing needs of consumers (i.e., by learning) and responding with goods and services to which superior value and greater satisfaction are consistently attributed. Thus, it is implied that a customer orientation is the basis for organizational learning that results in superior value attribution and greater customer satisfaction (Sinkula, Baker, and Noordewier 1997; Slater and Narver 1995). That is, being customer oriented allows firms to acquire and assimilate the information necessary to design and execute marketing strategies that result in more favorable customer outcomes.

However, although theory and some empirical research (e.g., Jaworski and Kohli 1993; Narver and Slater 1990; Van Egeren and O'Connor 1998) support the assumed or implied relationship between a customer orientation and business performance, the fundamental question as to how a customer orientation influences perceived performance from a customer's perspective has yet to be addressed. That is, the question as to how a customer-oriented service firm benefits from its customer focus, either directly or indirectly (through its impact on mediating variables), remains unknown. This is a critical gap in the literature if managers and researchers are to understand the benefits gained from implementing customer-oriented strategies. This study is intended to establish this link.

The primary objective of the study is therefore to assess how a firm's level of customer orientation influences consumers' evaluations of organizational performance and, 
ultimately, their outcome behaviors. In Figure 1, the specific relationships investigated are identified. The results of the investigation of these relationships indicate organizations that are perceived to be customer oriented reap multiple benefits. First, it is shown that customer orientation perceptions are positively associated with the evaluation of the quality of service. That is, customer orientation is positively related to the perceived quality of (a) the performance of a firm's employees, (b) the physical goods provided to customers, and (c) the firm's physical environment (i.e., its servicescape). Moreover, because service quality perceptions are positively associated with the satisfaction and value attributed to a service transaction, a strong customer orientation also improves (albeit, indirectly) the satisfaction and value attributed to an exchange and, ultimately, behavioral outcomes. Thus, an organization benefits both directly and indirectly from having a customer orientation (i.e., through the impact of being customer oriented on quality perceptions, and the resulting impact of quality perceptions on consumers' value and satisfaction attribution).

\section{THEORY: A CRITICAL GAP}

\section{A Marketing Strategy Perspective}

Since its introduction in the early 1950s, the marketing concept has represented a fundamental tenet of marketing thought. As the philosophical foundation of a market orientation (Jaworski and Kohli 1993), the marketing concept serves as the primary justification for the preeminent role of customers in the planning and execution of market strategies. To be customer oriented implies that a firm is actively engaged in the organization-wide generation, dissemination of, and responsiveness to, market intelligence (Kohli and Jaworski 1990). Usually, this term is described as an organizational culture that stresses the customer as the focal point of strategic planning and execution (Deshpandé, Farley, and Webster 1993; Jaworski, Kohli, and Sahay 2000; Steinman, Deshpandé, and Farley 2000). This culture should be pervasive throughout the company such that employees consistently exhibit customer-oriented behaviors, and consumers thereby become accustomed to this philosophy (Dobni, Ritchie, and Zerbe 2000).

The implementation of the marketing concept, or having a customer orientation, has been referred to as an overlooked fundamental principle of marketing (Deshpandé, Farley, and Webster 1993). As a result, although there is an ongoing appreciation for the relevance of organizational learning (i.e., identifying and adapting to consumers'

\section{FIGURE 1 \\ The Research Model}

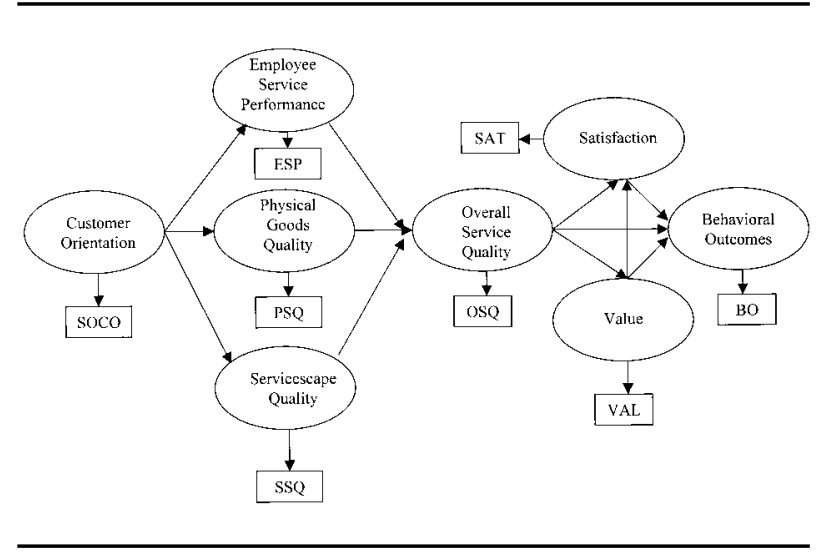

needs and wants) as a competitive strategy (e.g., Sinkula, Baker, and Noordewier 1997), much ambiguity exists relative to the true impact of "learning" on customer performance perceptions and, ultimately, on organizational strategies. To date, the emphasis has been on the examination of the role of organizational learning and market orientation as the organizational values or cultures that act as a precondition for market performance. Specifically, although some research has confirmed the positive relationship between being customer oriented and performance (e.g., Deshpandé, Farley, and Webster 1993; Jaworski and Kohli 1993), the critical linkage between customer orientation and customer perceptions has received little empirical attention (Day and Wensley 1988; Walker and Ruekert 1987). This is particularly true for service industries. This despite the fact that the most fundamental consequence of a customer orientation is found in the customers' perceptions of the goods and services offered by a firm.

\section{A Service Research Perspective}

Within the service literature, much effort has been devoted to identifying the antecedents of consumers' intended behavior. However, to date, these efforts have focused primarily on establishing the links between service quality, service value, satisfaction, and purchase intentions. The result is that we now have a better understanding of the conceptual realm of these variables, as well as how they relate to each other. These relationships are built into the research model depicted in Figure 1. Specifically, overall service quality is conceptualized as composed of three subdimensions: employee service performance, physical goods quality, and servicescape quality (cf. McAlexander, Kaldenberg, and Koenig 1994; McDougall 
and Levesque 1994; Rust and Oliver 1994). Customer satisfaction and value are identified as functions of consumers' service quality perceptions (Athanassopoulos 2000; Chenet, Tynan, and Money 1999; Fornell et al. 1996; Hallowell 1996), and all three are posited to directly affect purchase outcomes (E. W. Anderson and Sullivan 1993; Cronin et al. 1997; Ennew and Binks 1999; Gotlieb, Grewal, and Brown 1994; Ostrom and Iacobucci 1995; Sweeney, Soutar, and Johnson 1999; Taylor 1997).

The missing component in this model, and others like it, is a consideration of the organizational culture that creates these positive linkages. Indeed, Parasuraman (1987) reports that in the early stages of service marketing discussions, considerable dialogue was devoted to the importance of organizations having a customer orientation. In fact, it was listed as one of three factors critical to the success of a service organization. Unfortunately, since then, few studies have considered this variable in service encounter conceptualizations. One might surmise that the problem is a lack of a clear understanding of what it means for a service organization to be customer oriented and how this fits into established service marketing paradigms.

Hoffman and Ingram (1992) argue that, for a service organization, being customer oriented is akin to practicing the "marketing concept" at the customer level. This means that such firms actively pursue employees who "engage in behaviors that lead to long-term customer satisfaction" (p. 69). The managerial goal is therefore to establish an organizational culture that fosters these employee behaviors. The intended outcome of course is the development of positive customer performance perceptions and, ultimately, favorable behavioral outcomes. Otherwise stated, a customer orientation is part of a cultural foundation that results in positive customer perceptions (Dobni, Ritchie, and Zerbe 2000). This culture is instilled in employees through training regimens and through the dissemination of cultural norms. For many service organizations, it is most evident on the front line where interaction and employee behaviors are easily assessed (Katzenbach and Santamaria 1999). This view is captured conceptually in Beatty's (1988) framework where "people-oriented" organizations lead to customer-oriented employee behaviors, which, in turn, create customer perceptions consistent with this orientation (p. 409).

Thus, despite the advancements of both the strategy and service literatures in understanding the mechanisms that govern the effects of a customer-oriented culture on firm performance, several critical questions remain. For instance, once such a culture is established, is there an identifiable direct effect on consumers' perceptions of an organization's market strategies (i.e., are they customer oriented?) and ultimately (i.e., indirectly through such mediating variables as consumers' satisfaction and value at- tributions) on their behavioral outcomes? If a firm successfully implements a "customer-oriented" culture and is so perceived in the marketplace, are customers more likely to respond positively to the organization's goods and services? Are an organization's transactions with its customers thereby more likely to result in positive outcomes for the organization? These are questions that must be addressed if the contributions of an organization's cultural values are to be fairly assessed and the value of being customer oriented firmly established in management culture and practice.

\section{CONCEPTUAL DEVELOPMENT AND RESEARCH HYPOTHESES}

By nature, services are intangible and characterized by an inability to separate production from consumption. As a result, in a service setting, a customer-oriented culture is identified by the behaviors of its employees above all else (Cran 1994; Mahajan et al. 1994; C. Webster 1990). Good service is often described as a willingness to go "above and beyond" or to "go the extra mile." Service firms with renowned customer orientation reputations have developed corporate cultures that demand these behaviors of their personnel. It is in this context that we view the customer orientation variable. That is, customer orientation defines employee behaviors that are indicative of a customeroriented culture.

The research reported here investigates the effects of being customer oriented across a set of diverse service providers to assess the relative importance of this aspect of organizational service culture. The theory discussed above reveals that the culture of a customer-oriented organization positions the firm to better understand the needs and wants of its customers (i.e., to exhibit a high level of organizational learning as a result of its customer orientation). This alone is envisioned to lead to more favorable customer-organization outcomes simply because the organization is better able to create and maintain superior customer value strategies. Marketers have long recognized that all product evaluations involve physical good and service dimensions (Rathmell 1966). As a result, a thorough investigation of the effect of a customer orientation on a service firm's execution of its marketing strategies must also recognize that such effects are also composed of multiple dimensions (i.e., physical good, service, and environmental strategies). Specifically, an increase in the customer orientation of a business is theorized to result in the identification of strategies that lead to customers having higher perceptions of the quality of an organization's physical goods, environment, and services. This leads to the first research hypothesis. 
Hypothesis 1: Customer orientation is directly related to customer perceptions of service employee performance, the service environment, and any physical goods included in the service encounter.

The service literature is replete with references to the importance of developing a customer orientation. In some instances, this is referred to as a "service orientation" (Cran 1994), whereas in others, it is included as a component of a market orientation for service firms (Van Egeren and O'Connor 1998). The overriding emphasis, however, is that this distinction emanates from employee behaviors and drives perceived performance and outcome measures (Hoffman and Ingram 1992). However, thus far, this relationship has only been supported theoretically. For instance, Slater and Narver (1995) argue that fostering a customer-oriented culture leads to the creation and maintenance of customer value. They go on to argue that this also leads to a firm that is well positioned to anticipate the needs of its customers and to offer goods and services that satisfy these needs. Kelley (1992) adopts a similar position concerning the outcome of a customer orientation in arguing that service firms with this type of culture generate employees who "engage in behaviors that increase the satisfaction of their customers" and lead "to the development of long-term relationships" (p. 27). As a result, a strong customer orientation is pervasive in the development of consumer performance perceptions in that it has been tied conceptually to improved service quality perceptions (Cran 1994; Hoffman and Ingram 1992), superior value (Gale 1994; Slater and Narver 1995), enhanced satisfaction (Kelley 1992), and more favorable behavioral outcomes (Hoffman and Ingram 1992; Kelley 1992). This leads to the second research hypothesis.

Hypothesis 2: Customer orientation is indirectly related to customer perceptions of overall service quality, value, satisfaction, and behavioral outcomes.

\section{METHODOLOGY}

\section{The Sample}

It is established that the evaluation of how customer oriented an organization is should be based on responses from a firm's customers (Deshpandé, Farley, and Webster 1993). Therefore, the hypotheses were tested using a sample of 649 consumers recruited by trained student assistants. Specific directions pertaining to the recruitment and observation of respondents were given to both better represent the population and to ensure the authenticity of the data. Supervisors (faculty members and Ph.D. candidates) were available to answer questions and to manage the data collection. Responses were collected in multiple locations in a medium-sized metropolitan area.

The study focused on three specific service industries that were identified to represent a wide array of service experiences and because each allows the respondents (albeit disproportionally) to assess the quality of the performance of employees, the physical environment, as well as the physical attributes that accompany the service. Two service providers per industry were assessed that were chosen on the basis of their visibility in the area. They included two regional express auto lubrication centers (i.e., service on a good), two nationally known amusement parks (i.e., a service consumed on site), and both a national and regional video rental store (i.e., a service with an accompanying physical good). To further improve the representativeness and comprehensiveness of the data, in each industry, roughly half of the surveys were collected at a transactionspecific level (i.e., "assess your last visit"), whereas the other half were cumulative responses (i.e., "assess a typical visit"). To be included in the sample, at least one experience with the service provider in the previous 6 months was required. The sample demographics for the overall and individual samples are presented in Table 1. The sample profile matches the regional population well with the exception that there were fewer "older" (i.e., age 56 and older) and African American respondents in the sample, and the respondents were generally better educated and contained more Hispanics than the population as a whole. However, this is not an uncommon distribution because many of the responses came from a metropolitan area that is dominated by two universities and a community college. This often leads to samples that appear more educated and younger than the population as a whole due to the fact that a large number of the college students are part-time residents of the area and are not included in the area's census count. The data were gathered at a time when classes were in session.

\section{The Measures}

Established scales were used, or adapted for use, where possible to measure each of the investigated constructs. However, two of the measures (value and physical goods quality) were developed for this study. In both cases, the measures were developed via successive stages of scale development (cf. Churchill 1979). All of the items were measured on 9-point Likert-type and semantic differential scales. Where necessary, the survey questions were slightly adapted to reflect the industries and the specific service providers investigated.

Customer Orientation (CO) was measured by using the 12 positively worded items from the Sales Orientation/ 
TABLE 1

Demographics of Industry Samples

\begin{tabular}{|c|c|c|c|c|c|}
\hline \multirow[b]{2}{*}{ Demographics } & \multicolumn{5}{|c|}{ Industry } \\
\hline & $\begin{array}{c}\text { Overall } \\
(\mathrm{N}=649)\end{array}$ & $\begin{array}{l}\text { Auto Lube } \\
(\mathrm{n}=196)\end{array}$ & $\begin{array}{c}\text { Amusement } \\
(\mathrm{n}=222)\end{array}$ & $\begin{array}{l}\text { Video Rental } \\
(\mathrm{n}=231)\end{array}$ & Regional Population \\
\hline \multicolumn{6}{|l|}{ Age } \\
\hline Under 25 & 43.1 & 46.9 & 44.2 & 39.1 & 31.5 \\
\hline 26 to 35 & 22.2 & 20.4 & 22.6 & 23.4 & 16.4 \\
\hline 36 to 55 & 23.9 & 21.9 & 24.4 & 25.1 & 24.0 \\
\hline 56 and older & 8.0 & 8.7 & 6.9 & 8.5 & 28.1 \\
\hline Missing & 0.3 & 0.1 & 0.0 & 0.5 & \\
\hline \multicolumn{6}{|l|}{ Gender } \\
\hline Male & 51.5 & 57.4 & 45.8 & 42.8 & 48.4 \\
\hline Female & 48.5 & 42.6 & 54.2 & 57.2 & 51.6 \\
\hline \multicolumn{6}{|l|}{ Ethnic status } \\
\hline Caucasian & 85.1 & 84.2 & 84.8 & 86.0 & 83.1 \\
\hline African American & 5.7 & 5.6 & 6.0 & 5.9 & 13.6 \\
\hline Hispanic & 6.8 & 7.7 & 6.0 & 6.8 & 2.0 \\
\hline Asian & 1.2 & 1.0 & 2.3 & 0.4 & 1.2 \\
\hline Other & 1.2 & 1.5 & 1.0 & 0.9 & 2.0 \\
\hline \multicolumn{6}{|l|}{ Education } \\
\hline Less than high school & 1.5 & 0.5 & 0.4 & 2.9 & 6.5 \\
\hline High school graduate & 7.6 & 5.6 & 8.8 & 8.1 & 20.7 \\
\hline Some college & 48.4 & 46.4 & 45.2 & 53.2 & 13.3 \\
\hline College graduate & 25.7 & 28.1 & 26.7 & 23.0 & 12.8 \\
\hline Some postgraduate work & 7.6 & 7.7 & 10.6 & 4.7 & \\
\hline Graduate degree & 9.2 & 11.7 & 8.3 & 8.1 & 4.3 \\
\hline \multicolumn{6}{|l|}{ Income/year } \\
\hline Less than $\$ 20,000$ & 26.5 & 28.0 & 23.0 & 28.4 & 35.2 \\
\hline$\$ 20,000$ to $\$ 39,999$ & 23.8 & 20.6 & 27.0 & 23.7 & 33.6 \\
\hline$\$ 40,000$ to $\$ 59,999$ & 17.1 & 18.5 & 15.2 & 17.5 & 17.3 \\
\hline$\$ 60,000$ to $\$ 75,000$ & 13.4 & 9.0 & 16.2 & 14.7 & 2.3 \\
\hline More than $\$ 75,000$ & 18.0 & 22.8 & 17.6 & 14.2 & 7.9 \\
\hline Missing & 1.2 & 1.0 & 1.0 & 1.4 & 3.7 \\
\hline
\end{tabular}

Customer Orientation (SOCO) scale (Saxe and Weitz 1982). This scale was originally designed to measure the customer orientation of sales personnel so its wording was modified to reflect the consumers' point of view and also the characteristics of the three services investigated. The items cover a broad range of issues that are indicative of customer-oriented employee behaviors, such as whether the employees had the customer's best interest in mind, answered the customer's questions, helped solve any problems that arose, and whether they provided an accurate expectation of service product performance. For a more complete list of these items, and a discussion of their origin, refer to Saxe and Weitz (1982). The coefficient alpha estimate for this scale was .93, and the parameter estimates ranged from .50 to .81 .

A three-item bipolar adjective scale was developed to assess Physical Goods Quality (PGQ). The measure asked respondents to assess the quality of any accompanying physical goods that were part of the service as delivered. The items were similar to the service quality scale devel- oped by Oliver (1997), with the exception that the respondents were specifically directed to assess the quality of the "physical products" received during the transaction. The adjectives employed ranged from poor to excellent, low quality to high quality, and one of the worst to one of the best. The coefficient alpha estimate for the scale was .94, whereas the parameter estimates ranged from .90 to .95 .

A 26-item Servicescape Quality (SSQ) scale modified from previously reported studies (e.g., Bitner 1992; J. Baker, Levy, and Grewal 1992) was used to assess perceptions of the physical environment. The scale required the respondent to rate 26 aspects of the physical environment in accordance with the servicescape dimensions suggested by Bitner (1992) (e.g., the design, ambiance, and any accompanying signs, symbols, and artifacts). The scale evaluates the quality of such environmental aspects as the "lighting," "parking," "attractiveness," and "accessibility."

A five-item performance-based Service Quality (PSQ) scale similar to ones used elsewhere in the literature (e.g., 
Gotlieb, Grewal, and Brown 1994; Hartline and Ferrell 1996) was used to measure the quality of the organizations' (employee) service performance. The measure incorporated the dimensions identified by Parasuraman, Zeithaml, and Berry (1988) and was developed as part of another study. Specifically, the five items assessed the degree to which the service received was "reliable," "trustworthy," and "delivered in a timely manner," as well as whether the employees were dressed neatly and whether they made an effort to understand the customer's needs. The coefficient alpha estimate for the PSQ scale was .90, whereas the parameters ranged from .65 to .88 .

A three-item Overall Service Quality (OSQ) scale was used to measure consumers' perceptions of overall quality of their service transaction. The items were based on the overall service quality measure reported by Teas (1993). Adjectives were used to describe the quality of service and ranged from inferior to superior, low quality to high quality, and whether the service provider adhered to low standards or high standards. The coefficient alpha estimate for the scale was .95 . The parameter estimates ranged from .91 to .94 .

Customer Satisfaction (SAT) was measured using a three-item unipolar adjective scale adapted from Westbrook and Oliver (1991). Due to the evidence that satisfaction is primarily an affectively oriented construct (cf. Oliver 1997), the adjectives used were emotive in nature. Respondents were asked to report the degree to which they were happy, pleased, and delighted. The coefficient alpha estimate for the scale was .92, and the parameter estimates ranged from .85 to .92 .

A three-item Value (VAL) scale was also constructed for the study. The items were developed to reflect the conceptualization of value as composed of relative "gets" versus "gives" (Zeithaml 1988) and were scaled from very low to very high. The items assessed the "value of the service product received," the value of "what was received relative to what was paid," and whether the overall service experience delivered "good value." The coefficient alpha estimate for the value scale was .76, whereas the parameter estimates ranged from .60 to .81 .

A four-item Behavioral Outcomes (BO) scale was adapted from Zeithaml, Berry, and Parasuraman (1996). The items reflect the multiple dimensions of behavioral outcomes identified in that study, including repurchase intentions, customer loyalty, and word-of-mouth intentions. Respondents were asked to assess "the probability that they would use the service again," whether they would "recommend the service to a friend," "the likelihood that they would say good things to others," and their "loyalty" to the service firm. The coefficient alpha estimate for the behavioral outcomes scale was .91. The parameter estimates ranged from .79 to .92 .

\section{ANALYSIS AND RESULTS}

The research model was tested using the two-step approach recommended by J. Anderson and Gerbing (1988). First, the items were tested in a comprehensive confirmatory factor analysis. The items were constrained to load on their respective factors and were not allowed to cross-load on other factors. All of the items were included in the analysis, with the exception of the servicescape scale, which is formative. Various descriptive statistics (correlations, shared variances, and average variances extracted) are reported in Table 2, as are the results of the measurement model testing. Reliability was assessed via the coefficient alpha estimates that are also reported in Table 2.

The analysis of the measurement model revealed a good fit to the data. Although the chi-square estimate was significant, this statistic is known to be sensitive to sample size (Gerbing and Anderson 1993). As a result, emphasis is placed on the Comparative Fit Index (CFI), Tucker-Lewis Index (TLI), and the root mean square error of approximation (RMSEA) due to their relative stability, insensitivity to sample size (J. Anderson and Gerbing 1984; Gerbing and Anderson 1993), and the recent advances reported in identifying acceptable cutoff values (Hu and Bentler 1999). For the measurement model, the TLI and CFI estimates were above the recommended threshold (.95), and the RMSEA was slightly above its cutoff criterion at .07 (see Table 2).

The validity of the scales was tested using the procedure recommended by Fornell and Larcker (1981). Convergent validity was assessed by verifying the significance of the $t$ values associated with the parameter estimates. All $t$ values were positive and significant $(p \leq .001)$. Discriminant validity was tested by comparing the average variance extracted by each construct to the shared variance between the construct and all other variables. For each comparison, the explained variance exceeded all combinations of shared variances (see Table 2).

Testing of the hypothesized model (see Figure 1) was accomplished through structural equation modeling via the use of Amos 4.0. Table 3 presents the detailed results of the comprehensive model testing. Similar to the measurement model, the structural model also fit the data well with the CFI, TLI, and RMSEA estimates either well above or approaching the recommended cutoff values (CFI, TLI $=$ .97 , RMSEA $=.08$ ). The relative ability of the hypothesized model to explain variation in the seven endogenous variables, as measured by the $R^{2}$ value for the respective equations (see Table 3), ranged from .23 (servicescape quality) to .75 (overall service quality). The $R^{2}$ value for behavioral outcomes was .67. As expected, the hypothesized paths between overall service quality, satisfaction, value, and behavioral outcomes were all positive and sig- 
TABLE 2

Scale Analysis Results

\begin{tabular}{|c|c|c|c|c|c|c|c|c|c|c|}
\hline Variable & Coefficient Alpha & $A V E$ & $\mathrm{CO}$ & $P S Q$ & $P G Q$ & $S S Q$ & $O S Q$ & SAT & $V A L$ & BO \\
\hline Customer Orientation (CO) & .93 & .55 & 1.00 & $.36^{\mathrm{a}}$ & .21 & .14 & .30 & .27 & .19 & .17 \\
\hline Performance Service Quality (PSQ) & .90 & .64 & .60 & 1.00 & .48 & .34 & .61 & .55 & .36 & 41 \\
\hline Physical Goods Quality (PGQ) & .94 & .84 & .46 & .69 & 1.00 & .25 & .56 & .40 & .35 & .35 \\
\hline Servicescape Quality (SSQ) & - & - & .38 & .58 & .50 & 1.00 & .30 & .37 & .32 & .30 \\
\hline Overall Service Quality (OSQ) & .95 & .86 & .55 & .78 & .75 & .55 & 1.00 & .53 & .32 & .44 \\
\hline Satisfaction (SAT) & .92 & .80 & .52 & .74 & .63 & .61 & .73 & 1.00 & .32 & .46 \\
\hline Value (VAL) & .76 & .47 & .44 & .60 & .59 & .57 & .57 & .57 & 1.00 & .36 \\
\hline Behavioral Outcomes (BO) & .91 & .73 & .42 & .64 & .59 & .55 & .66 & .68 & .60 & 1.00 \\
\hline
\end{tabular}

NOTE: Confirmatory factor analysis results: $N=649, \chi^{2}=2101.6 / 474$ degrees of freedom, Comparative Fit Index $=.98$, Tucker-Lewis Index $=.98$, root mean square error of approximation $=.07, \mathrm{AVE}=$ average variance extracted.

a. Shared variances are reported in the upper half of the matrix.

nificant (see Table 3), thus supporting the relationships specified in the service literature (e.g., Cronin, Brady, and Hult 2000; Fornell et al. 1996; Gotlieb, Grewal, and Brown 1994). The results of the analyses specific to the individual hypotheses are presented next.

Based on the conceptual support in the literature that customer orientation is associated with customer performance perceptions (e.g., Hoffman and Ingram 1992), the first research hypothesis defines direct links between customer orientation and the three components of service quality (i.e., PGQ, SSQ, and PSQ). These paths were positive and significant $(p \leq .001)$, thereby supporting Hypothesis 1 . The second hypothesis tests the indirect links between customer orientation and overall service quality, satisfaction, value, and behavioral outcomes. As hypothesized, each of these paths was also significant and positive.

To improve the generalizability of the results, the research model was also tested in the three industries individually. The fit of the models was similar to that reported in the aggregated sample, with the CFI and TLI estimates ranging from .96 to .98 and RMSEA ranging from .08 to .09. The specified paths were also similar, with three exceptions. The servicescape $\rightarrow$ overall service quality paths were not significant in either the auto lube or video rental samples, and the satisfaction $\rightarrow$ behavioral outcomes path was not significant in the video rental sample. For the latter, stronger associations were noted between service quality, value, and outcome behavior. As to the servicescape links, this could be expected given the nature of the services, as they are both dominated by physical goods components and less so by the aesthetics of the physical environment. This is especially true when compared to the importance of the servicescape to customer perceptions of amusement parks.

In addition, we also empirically tested the causal order specified in the model. The objective was simply to pro-

\section{TABLE 3}

Results of Comprehensive Model Testing

\begin{tabular}{|c|c|c|c|}
\hline Path & $\begin{array}{l}\text { Path Coefficient } \\
\quad(\mathrm{p} \text { value })\end{array}$ & $\mathrm{R}^{2}$ & Fit Indices \\
\hline \multicolumn{4}{|l|}{ Direct paths } \\
\hline$(\mathrm{CO} \rightarrow \mathrm{PSQ})$ & $.52(\leq .001)$ & & \\
\hline$(\mathrm{CO} \rightarrow \mathrm{PGQ})$ & $.52(\leq .001)$ & .48 (PSQ) & $\begin{array}{c}\chi^{2}=2,898.85 \\
d f=515\end{array}$ \\
\hline$(\mathrm{CO} \rightarrow \mathrm{SSQ})$ & $.36(\leq .001)$ & .27 (PGQ) & $\mathrm{CFI}=.97$ \\
\hline$(\mathrm{PSQ} \rightarrow \mathrm{OSQ})$ & $.68(\leq .001)$ & .23 (SSQ) & $\mathrm{TLI}=.97$ \\
\hline$(\mathrm{PGQ} \rightarrow \mathrm{OSQ})$ & $.43(\leq .001)$ & .75 (OSQ) & RMSEA $=.08$ \\
\hline$(\mathrm{SSQ} \rightarrow \mathrm{OSQ})$ & $.27(\leq .01)$ & .66 (SAT) & \\
\hline$(\mathrm{OSQ} \rightarrow \mathrm{SAT})$ & $.58(\leq .001)$ & .53 (VAL) & \\
\hline$(\mathrm{OSQ} \rightarrow \mathrm{VALUE})$ & $.69(\leq .001)$ & $.67(\mathrm{BO})$ & \\
\hline$(\mathrm{OSQ} \rightarrow \mathrm{BO})$ & $.15(\leq .05)$ & & \\
\hline$(\mathrm{SAT} \rightarrow \mathrm{BO})$ & $.26(\leq .001)$ & & \\
\hline (VALUE $\rightarrow$ BO) & $.65(\leq .001)$ & & \\
\hline \multicolumn{4}{|l|}{ Indirect paths } \\
\hline$(\mathrm{CO} \rightarrow \mathrm{OSQ})$ & $.67(\leq .001)$ & & \\
\hline$(\mathrm{CO} \rightarrow \mathrm{SAT})$ & $.52(\leq .001)$ & & \\
\hline$(\mathrm{CO} \rightarrow \mathrm{VAL})$ & $.49(\leq .001)$ & & \\
\hline$(\mathrm{CO} \rightarrow \mathrm{BO})$ & $.46(\leq .001)$ & & \\
\hline
\end{tabular}

NOTE: $\mathrm{CO}=$ Customer Orientation; $\mathrm{PSQ}=$ Performance Service Quality; SSQ = Servicescape Quality; OSQ = Overall Service Quality; PGQ = Physical Goods Quality; SAT = Satisfaction; $\mathrm{BO}=$ Behavioral Outcomes; $\mathrm{VAL}=$ Value CFI = Comparative Fit Index; TLI = Tucker-Lewis Index; RMSEA = root mean square error of approximation.

vide tangible support for the research model as specified. Three competing model tests were performed where the research model was compared to three alternative conceptualizations that sequentially reversed the causal order between customer orientation and service quality, satisfaction and value. That is, each model differed only in the positioning of the customer orientation construct. In each case, repositioning customer orientation as an endogenous construct significantly decreased the model fit $(p \leq$ $.01)$, thereby supporting the research model. 


\section{DISCUSSION}

"Conventional marketing wisdom holds that a customer orientation provides a firm with a better understanding of its customers, which subsequently leads to enhanced customer satisfaction and firm performance" (Voss and Voss 2000, p. 67).

The purpose of this research was to assess the influence of a customer orientation on consumer perceptions of a service firm. As is evident from the above quote, customer orientation has been linked to firm performance. However, neither the strategy nor the service literatures have considered the implications of being customer oriented from a customer's perspective. This is particularly intriguing given that customer orientation was identified as a key managerial objective at the inception of service marketing theory. The results presented here support that theory in indicating that customer-oriented firms benefit at multiple levels. Significant relationships were reported that identify customer orientation as both directly and indirectly related to customer service perceptions (i.e., OSQ, SAT, and VAL) and outcome behaviors. The results thus offer support for the prevailing notion that having a customer orientation has a positive influence on customer perceptions and, ultimately, the performance of firms.

Perhaps the most important theoretical and empirical evidence presented was in relation to the direct effects of being customer oriented. Customer-oriented firms were consistently perceived as having better quality physical goods and employee performance. Moreover, this effect was also evident for perceptions of the servicescape, but only in industries where the physical environment is a focal point in the experience. Collectively, this indicates that customer-oriented firms are viewed as having more success in the execution of their market strategies. These findings emphasize the importance of having an organizational capacity to learn; that is, to identify and adapt to the needs and wants of consumers. For service providers to remain customer oriented, organizations must strive to generate, disseminate, and be responsive to customer information (Narver and Slater 1990). The initial reward for being customer oriented is favorable customer evaluations of employee performance (PSQ), physical goods (PGQ), and the servicescape (SSQ).

However, the benefits of being customer oriented do not end with customers' evaluations of the individual components of an organization's execution of its market strategies. The findings also indicate that overall perceptions of the quality of an organization's service transactions (OSQ) have both a direct and indirect impact on behavioral outcomes (BO). Specifically, from the perspective of customers, being customer oriented enhances the perceptions of the quality of an organization's overall market strategies, which, in turn, increases customer loyalty, repurchase, and the willingness to offer positive word-of-mouth recommendations.

These findings are particularly relevant for service managers who must satisfy ever-increasing customer service expectations. The results also justify practitioner interest in establishing a customer-oriented service culture (Katzenbach and Santamaria 1999; C. Webster 1990). Indeed, service firms that adopt customer-oriented strategies should gain a competitive advantage from these efforts. For instance, bank branch managers who make an effort to aggressively solicit customer comments should realize an improvement in customer satisfaction over the competition (Parasuraman 1987). So, the firm that hopes to excel in the 21 st century must become a learning organization; meaning a firm that benefits from its efforts to develop a superior customer orientation. This is a position gained from efforts to create, to acquire, and to transfer knowledge so as to modify its employees' behavior in ways designed to enhance the performance perceptions and satisfaction of its customers. This is particularly important for service organizations, for which customer retention is often more desired than competitive differentiation due to the greater profitability associated with repeat customers and the reliance of service firms on positive customer word-of-mouth communications in their promotional efforts.

A fundamental assumption of organizational learning theory is that establishing a customer-oriented culture is a necessary precondition for the creation of a "learning organization" (W. E. Baker and Sinkula 1999; Sinkula, Baker, and Noordewier 1997; Slater and Narver 1995). Indeed, the need to learn from customers is certainly not a revelation in management theory or practice. However, even those managers who are the most ardent believers in the need for market-driven strategies have traditionally had only limited contact with customers. Moreover, as organizations and markets become more globally diverse, customer needs and wants tend to be defined by secondhand information gathered from managers who have limited access to, and knowledge of, a firm's customers. Such restrictions on an organization's customer orientation result in poor decisions relative to service quality and physical good strategies (Gouillart and Sturdivant 1994). The results presented here indicate that the effects may be more far-reaching.

Specifically, these results suggest that marketing managers should endeavor to collect, to analyze, to disseminate, and to act on information about the needs and wants of consumers. This underscores the need for service organizations to have an effective and efficient market information system. Customer satisfaction and service quality assessments are mandated by our findings, as are systems 
to collect customer complaints and to enact service recovery efforts. Information about the brand-switching patterns of consumers can also aid marketing managers in their efforts to develop effective brand equity strategies for service organizations. The astute marketing manager will also remember the importance of frontline service employees. Their interactions with customers largely determine consumers' perceptions of their service experience. Internal service quality and employee satisfaction assessment therefore are also an integral part of a service organization's efforts to be customer oriented.

These results may also identify a threat faced by some service managers as they attempt to compete in a strong economy. Low unemployment rates can have an adverse affect on service levels as managers struggle to find and maintain strong service staffs (Rodriguez 2000). This is particularly true for entry-level positions and convenience-oriented industries. In such times, the reality is that service managers can ill-afford to lose even poor workers and that customer service ultimately suffers as a result. This threat is especially alarming given the extensive implications of such a decline on customer service perceptions and behavioral outcomes.

\section{LIMITATIONS AND RESEARCH IMPLICATIONS}

The research was based on the perceptions of three organizational types. Other types of service organizations might have produced similar or different findings. The study is also based on data gathered at a single point in time. Longitudinal data would enable changes in consumers' perceptions of the customer orientation of a specific organization to be assessed, and determinants of changes in perceptions could be identified. Although the cross-sectional approach enhances the generalizability of the findings, it limits the ability to make causal inferences from the data. The sample is somewhat skewed in favor of younger, more well-educated consumers and includes fewer African Americans and more Hispanics than the population from which the data are drawn. Application of the results beyond these parameters should be approached with caution.

The results of this study suggest that additional efforts appear well justified. Much is still to be discovered relative to the process of forming perceptions of customer orientation. Investigating the role of competitor actions in this process also appears justified. Is the level of customer orientation attributed to competitors a factor in determining the contributions of a customer orientation to organizational performance? Individual differences also appear to be a worthy area for further study. Does age, gender, income, ethnic status, or education affect customer orientation perceptions? Are customers' level of related expertise, their experience with the product category, or their confidence in their own ability to judge goods and services factors that might also influence perceptions of a firm's customer orientation? The influence of brand equity on customer service perceptions is also clearly deserving of attention. Product class involvement, the risk associated with a purchase, and the importance of the purchase might be other factors worthy of investigation. To ignore such issues would be to fail to be customer oriented!

\section{REFERENCES}

Anderson, Eugene W. and Mary W. Sullivan (1993), "The Antecedents and Consequences of Customer Satisfaction," Marketing Science, $12,125-43$.

Anderson, James and David Gerbing (1984), "The Effect of Sampling Error on Convergence, Improper Solutions, and Goodness-of-Fit Indices for Maximum Likelihood Confirmatory Factor Analysis," Psychometrika, 49, 155-73.

_ and - (1988), "Structural Equation Modeling in Practice: A Review and Recommended Two Step Approach," Psychological Bulletin, 103 (May), 411-23.

Athanassopoulos, Antreas D. (2000), "Customer Satisfaction Cues to Support Market Segmentation and Explain Switching Behavior,' Journal of Business Research, 47, 191-207.

Baker, Julie, Michael Levy, and Dhruv Grewal (1992), “An Experimental Approach to Making Retail Store Environmental Decisions," Journal of Retailing, 68 (4), 445-60.

Baker, William E. and James M. Sinkula (1999), "The Synergistic Effect of Market Orientation and Learning Orientation on Organizational Performance," Journal of the Academy of Marketing Science, 27 (94), 411-27.

Beatty, Sharon (1988), “An Exploratory Study of Organizational Values with a Focus on People Orientation," Journal of Retailing, 64 (4), 405-25.

Bitner, Mary Jo (1992), "Servicescapes: The Impact of Physical Surroundings on Customers and Employees," Journal of Marketing, 56 (April), 55-71.

Chenet, Pierre, Carolyn Tynan, and Arthur Money (1999), "Service Performance Gap: Re-Evaluation and Redevelopment," Journal of Business Research, 46, 133-47.

Churchill, Gilbert A. (1979), “A Paradigm for Developing Better Measures of Marketing Constructs," Journal of Marketing Research, 16 (February), 64-73.

Cran, David J. (1994), “Towards Validation of the Service Orientation Construct," The Service Industries Journal, 14 (January), 34-44.

Cronin, J. Joseph Jr., Michael K. Brady, Richard R. Brand, Roscoe Hightower Jr., and Donald Shemwell (1997), "A Cross-Sectional Test of the Effect and Conceptualization of Service Value," Journal of Services Marketing, 11 (6), 375-91.

— - , and G. Tomas Hult (2000), "Assessing the Determinants of Consumer Behavioral Intentions in Service Environments: An Investigation of a Comprehensive Model of the Effects of Quality, Value, and Satisfaction," Journal of Retailing, 76 (2), 193-218.

Day, George S. and Robin Wensley (1988), "Assessing Advantage: A Framework for Diagnosing Competitive Superiority," Journal of Marketing, 52 (April), 1-20. 
Deshpandé, Rohit, John U. Farley, and Frederick E. Webster (1993), "Corporate Culture, Customer Orientation, and Innovativeness in Japanese Firms: A Quadrant Analysis," Journal of Marketing, 57 (January), 23-37.

- and Frederick E. Webster (1989), "Organizational Culture and Marketing: Defining the Research Agenda," Journal of Marketing, 53 (January), 3-15

Dobni, Dawn, J. R. Brent Ritchie, and Wilf Zerbe (2000), "Organizational Values: The Inside View of Service Productivity," Journal of Business Research, 47, 91-107.

Ennew, Christine T. and Martin R. Binks (1999), "Impact of Participative Service Relationships on Quality, Satisfaction, and Retention: An Exploratory Study," Journal of Business Research, 46, 121-32.

Fornell, Claes, Michael D. Johnson, Eugene W. Anderson, Jaesung Cha, and Barbara Everitt Bryant (1996), "The American Customer Satisfaction Index: Nature, Purpose, and Findings," Journal of Marketing, 60 (October), 7-18

and D. F. Larcker (1981), "Evaluating Structural Equations Models with Unobservable Variables and Measurement Error," Journal of Marketing Research, 18 (February), 39-50.

Gale, Bradley T. (1994). Managing Customer Value. New York: Free Press.

Gerbing, David W. and James C. Anderson (1993), "Monte Carlo Evaluations of Goodness of Fit Indices for Structural Equation Models," in Testing Structural Equation Models, Kenneth A. Bollen and J. Scott Long, eds. Newbury Park, CA: Sage.

Gotlieb, Jerry B., Dhruv Grewal, and Stephen W. Brown (1994), "Consumer Satisfaction and Perceived Quality: Complementary or Divergent Constructs?" Journal of Applied Psychology, 79 (6), 875-85.

Gouillart, Francis J. and Frederick D. Sturdivant (1994), "Spend a Day in the Life of Your Customers," Harvard Business Review, JanuaryFebruary, 116-26.

Hallowell, Roger (1996), "The Relationship of Customer Satisfaction, Customer Loyalty, and Profitability: An Empirical Study," International Journal of Service Industry Management, 7 (4), 27-42.

Hartline, Michael D. and O. C. Ferrell (1996), "The Management of Customer-Contact Service Employees: A Empirical Investigation," Journal of Marketing, 52 (October), 52-70.

Hoffman, Douglas K. and Thomas N. Ingram (1992), "Service Provider Job Satisfaction and Customer Oriented Performance," Journal of Services Marketing, 6 (2), 68-78.

Houston, Franklin S. (1986), "The Marketing Concept: What It Is and What It Is Not," Journal of Marketing, 50 (April), 81-87.

Hu, Li-tze and Peter M. Bentler (1999), "Cutoff Criteria for Fit Indexes in Covariance Structure Analysis: Conventional Criteria versus New Alternatives," Structural Equation Modeling, 6 (1), 1-55.

Jaworski, Bernard and Ajay Kohli (1993), "Market Orientation: Antecedents and Consequences," Journal of Marketing, 52 (July), 53-70.

_ $\longrightarrow$, and Arvind Sahay (2000), "Market Driven versus Driving Markets," Journal of the Academy of Marketing Science, 28 (1), 45-54.

Katzenbach, Jon R. and Jason A. Santamaria (1999), "Firing up the Front Line," Harvard Business Review, May-June, 107-17.

Kelley, Scott W. (1992), "Developing Customer Orientation among Service Employees," Journal of the Academy of Marketing Science, 20 (1), 27-36.

Kohli, Ajay K. and Bernard J. Jaworski (1990), "Market Orientation: The Construct, Research Propositions, and Managerial Implications," Journal of Marketing, 54 (April), 1-18.

Mahajan, Jayashree, Asoo J. Vakharia, Pallab Paul, and Richard B. Chase (1994), "An Exploratory Investigation of the Interdependence between Marketing and Operations Functions in Service Firms," International Journal of Research in Marketing, 11, 1-15.

McAlexander, James H., Dennis O. Kaldenberg, and Harold F. Koenig (1994), "Service Quality Measurement," Journal of Health Care Marketing, 3 (Fall), 34-40.
McDougall, Gordon H. G. and Terrence J. Levesque (1994), "A Revised View of Service Quality Dimensions: An Empirical Investigation," Journal of Professional Services Marketing, 11 (1), 189-209.

Narver, John C. and Stanley F. Slater (1990), "The Effect of a Market Orientation on Business Profitability," Journal of Marketing, 54 (October), 20-35.

Oliver, Richard L. (1997), Satisfaction: A Behavioral Perspective on the Consumer. New York: McGraw-Hill.

Ostrom, Amy and Dawn Iacobucci (1995), "Consumer Trade-Offs and the Evaluation of Services," Journal of Marketing, 59 (January), $17-28$.

Parasuraman, A. (1987), "Customer Oriented Corporate Cultures Are Crucial to Services Marketing Success," Journal of Services Marketing, 1 (1), 39-46.

- Valerie A. Zeithaml, and Leonard L. Berry (1988), "SERVQUAL: A Multiple-Item Scale for Measuring Consumer Perceptions of Service Quality," Journal of Retailing, 64 (1), 12-40.

Rathmell, John M. (1966), "What Is Meant by Services," Journal of Marketing, 30 (October), 32-36.

Rodriguez, Cindy (2000), "Service with a Shrug," The Boston Globe, January 16, A01.

Rust, Roland T. and Richard L. Oliver (1994), "Service Quality: Insights and Managerial Implications from the Frontier," in Service Quality: New Directions in Theory and Practice, Roland T. Rust and Richard L. Oliver, eds. Thousand Oaks, CA: Sage.

Saxe, Robert and Barton A. Weitz (1982), "The SOCO Scale: A Measure of the Customer Orientation of Salespeople," Journal of Marketing Research, 19 (August), 343-51.

Shapiro, Benson P. (1988), "What the Hell Is 'Market Oriented?"' Harvard Business Review, 66 (November-December), 119-25.

Sinkula, James M., William E. Baker, and Thomas Noordewier (1997), "A Framework for Market-Based Organizational Learning: Linking Values, Knowledge and Behavior," Journal of the Academy of Marketing Science, 25 (Fall), 305-18.

Slater, Stanley and John C. Narver (1995), "Market Orientation and the Learning Organization," Journal of Marketing, 59 (July), 162-67.

Steinman, Christine, Rohit Deshpandé, and John U. Farley (2000), "Beyond Market Orientation: When Customers and Suppliers Disagree," Journal of the Academy of Marketing Science, 28 (1), 109-19.

Sweeney, Jillian C., Geoffrey N. Soutar, and Lester W. Johnson (1999), "The Role of Perceived Risk in the Quality-Value Relationship: A Study in a Retail Environment," Journal of Retailing, 75 (1), 77-105.

Taylor, Steven A. (1997), "Assessing Regression-Based Importance Weights for Quality Perceptions and Satisfaction Judgments in the Presence of Higher Order and/or Interaction Effects," Journal of Retailing, 73 (1), 135-59.

Teas, R. Kenneth (1993), "Expectations, Performance Evaluation, and Consumers' Perception of Quality," Journal of Marketing, 57 (October), 18-34

Van Egeren, Marsha and Stephen O'Connor (1998), "Drivers of Market Orientation and Performance in Service Firms," Journal of Services Marketing, 12 (1), 39-58.

Voss, Glenn B. and Zannie G. Voss (2000), "Strategic Orientation and Firm Performance in an Artistic Environment," Journal of Marketing, 64 (January), 67-83.

Walker, Orville C. and Robert W. Ruekert (1987), "Marketing's Role in the Implementation of Business Strategies: A Critical Review and Conceptual Framework," Journal of Marketing, 51 (July), 15-33.

Webster, Cynthia (1990), "Toward the Measurement of the Marketing Culture of a Service Firm," Journal of Business Research, 21, 345-62.

Webster, Frederick E. Jr. (1988), "Rediscovering the Marketing Concept," Business Horizons, 31 (May-June), 29-39. 
Westbrook, Robert A. and Richard L. Oliver (1991), "The Dimensionality of Consumption Emotion Patterns and Consumer Satisfaction," Journal of Consumer Research, 18 (June), 84-91.

Zeithaml, Valarie A. (1988), "Consumer Perceptions of Price, Quality, and Value: A Means-End Model and Synthesis of Evidence," Journal of Marketing, 52 (July), 2-22.

- Leonard Berry, and A. Parasuraman (1996), "The Behavioral Consequences of Service Quality," Journal of Marketing, 60 (April), 31-46.

Michael K. Brady is an assistant professor at Boston College. He earned a Ph.D. in marketing from Florida State University in 1997. His research interests are in the areas of service quality, customer satisfaction, service recovery, and service branding issues. His research has been published in the Journal of Retailing, the Journal of Business Research, the Journal of Services Marketing, the International Journal of Service Industry Management, as well as several national proceeding, including the American Marketing Association and Frontiers in Services Conference.
J. Joseph Cronin Jr. received his Ph.D. in marketing from the Ohio State University and has been a member of the Florida State University marketing faculty since 1986 . His primary research interests are in the areas of service quality and customer satisfaction, particularly as applied to sports, public transit, and managed health care issues. His work has appeared in the Journal of Marketing, the European Journal of Marketing, the Journal of Retailing, the Journal of Business Research, the Journal of the Academy of Marketing Science, the International Journal of Services Industry Management, the Journal of Services Marketing, the Journal of Health Care Marketing, and the Journal of Marketing Theory and Practice, among others. He currently serves on the editorial review boards of the Journal of Business Research, the International Journal of Services Industry Management, the Journal of Marketing Management, the Journal of Marketing Theory and Practice, and Health Marketing Quarterly. He is also an ad hoc reviewer for the Journal of Marketing, the Journal of Marketing Research, the Journal of Retailing, and the Journal of the Academy of Marketing Science. In addition, he serves as a review committee member for the Transit Cooperative Research Program (TCRP) administered by the National Academy of Sciences and the Transportation Research Board and on the Center for Clean Air Policy Public Transit RePositioning Dialogue Group. 